\title{
"THE EMERALDS OF YOUR FACE": METAPHOR AND METONYMY IN SOME EXPRESSIONS ${ }^{1}$
}

\author{
J avier Herrero R uiz \\ Universidad de La Rioja
}

RESU MEN : Este artículo se basa en el trabajo de Ruiz de Mendoza y Díez (2002), donde se afirma que la interacción conceptual está regulada y constreñida por un número limitado de patrones de interacción. Pretendemos apoyar esta tesis con el análisis y el estudio de varias expresiones relativas a "los ojos" (como to keep an eye on someone, to turn a blind eye to something, to feast one's eyes on something, to be the owner of somebody's eyes, to be the apple of somebody's eyes, etc.), que son representativas de varios patrones de interacción y que han sido extraídas tras un exhaustivo análisis de más de 500 ejemplos del BNC y del Oxford Superlex Dictionary.

D esde el análisis de patrones diferentes, proponemos dos operaciones de interacción posibles, secuenciación e integración, y defendemos que la comprensión de estas operaciones puede arrojar luz en torno a la distinción entre metáfora y metonimia. Además, pensamos que la forma que toma el proceso de secuenciación en un patrón de interacción está ligada al estatus ontológico del resultado de un proceso de integración.

ABSTRACT: The present paper elaborates on some of the ideas in Ruiz de Mendoza \& Díez (2002), where it is argued that conceptual interaction is fully regulated and constrained by a limited set of interactional patterns. This paper attempts to provide further evidence in support of this thesis through the analysis and exploration of several "eye expressions" (among others to keep an eye on someone, to turn a blind eye to something, to feast one's eyes on something, to be the owner of somebody's eyes, to be the apple of somebody's eyes, etc.), representative of various interactional patterns, and that have been extracted after an exhaustive analysis of more than 500 instances from both the BNC and the 0 xford Superlex Dictionary database.

On the basis of the analysis of the various patterns, we postulate two possible interaction operations, sequencing and integration, and argue that understanding these two operations sheds light on the definitional relationship between metaphor and metonymy. We also claim that the form sequential arrangement takes in an interactional pattern is related to the ontological status of the result of an integration process.

1. Financial support for this research has been provided by the DGI, Spanish Ministry of Education and Science, grant no. HUM 2004-05947-C02-01/FILO. The research has been cofinanced through FEDER funds. 
PALABRAS CLAVE: interacción conceptual, expresiones relativas a "los ojos", secuenciación, integración, metáfora, metonimia, etc. metonymy.

KEYWORDS: conceptual interaction, eye expressions, sequencing, integration, metaphor,

\section{Introduction}

Eyes are not only providers and suppliers of everyday experience for us, but they give hints and clues about our inner and emotional states as well. Through our eyes we can give clues as to our feelings of happiness, surprise, fear, and others. Because of that, besides being powerful extra-linguistic elements of great interest for the study of non-verbal communication, they are also crucial to understand cognitive modelling based on experience. N ot surprisingly, we find in language extensive evidence of several pervasive metaphorical and metonymic patterns related to the 'eyes' notion which are most interesting for a cognitive linguistics analysis. There is ample evidence that metaphor and metonymy are grounded in experience (cf. Lakoff \& Johnson, 1980, 1999; Lakoff, 1993) and 'eye' expressions are further evidence to that effect.

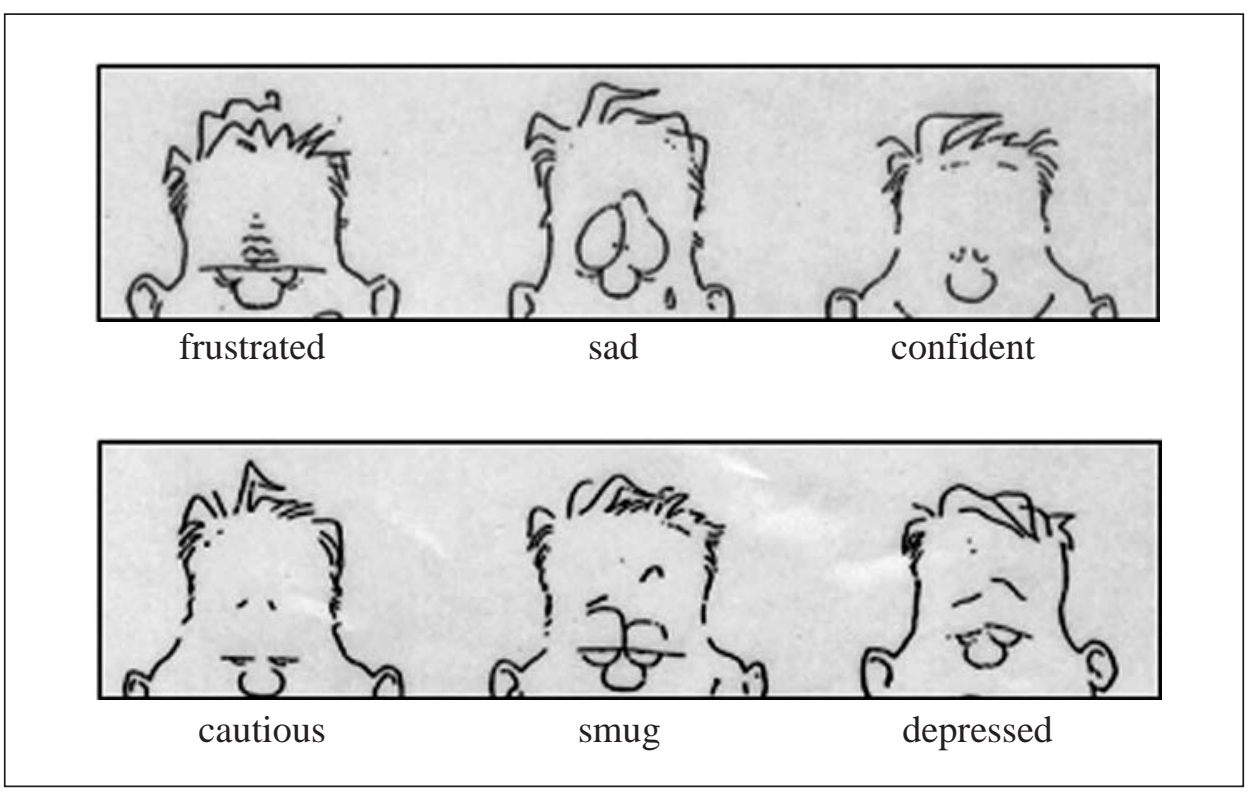

Figure 0 . Eyes reflecting different emotional states. 
In order to show this diversity, this paper analyses different "eye expressions" that have been extracted after an exhaustive search of more than 500 instances from the British National Corpus and the 0 xford Superlex Dictionary database, and which are representative of various interactional patterns concerning metaphor and metonymy.

Our analysis of the data has also allowed us to make a distinction between two interaction operations, namely sequencing and integration, which have not been discussed in the literature.

However, before going into the intricacies of 'eye' expressions in English, we will first devote a preliminary section to the description and classification of the cognitive phenomena upon which we are going to focus our analysis: metaphor and metonymy.

\section{Defining metaphor and metonymy}

Cognitive linguists have carried out a large quantity of studies on metaphor, an idealised cognitive model (or ICM ) which is the consequence of a conceptual mapping across different domains. So far, many authors have contributed to a formal distinction between metaphor and metonymy. Let us consider the basic differences as set out by Lakoff \& Johnson (1980: 35-40) and Lakoff \& Turner (1989: 103-104):

(1) In metaphor there are two conceptual domains involved, one being understood in terms of the other, while metonymy only involves one conceptual domain, i.e. the mapping occurs within a single domain and not across domains.

(2) In metaphor, the source domain is mapped onto the target domain, and thus it is mainly used for understanding, e.g. I have control over him (having control or force is up). In contrast, metonymy is mainly used for reference, as we can refer to an entity in a schema by referring to another entity in the same schema, e.g. Wall Street is in crisis (the street stands for the institution).

(3) Thus, the relationship between the source and target domains in metaphor is of the "IS A " kind; in metonymy there is a "STA NDS FOR" relationship, since one entity in a schema is taken as standing for another entity in the same schema or for the schema as a whole. 
H owever, as Ruiz de M endoza $(1997,1999)$ has noted, the only crucial difference between metaphor and metonymy is related to the domain-internal and domain-external nature of the mappings respectively, since both metaphor and metonymy can be used either referentially or non-referentially (i.e. predicatively):

\section{METAPHOR:}

- Used referentially: The pig is waiting for his bill (the pig is the customer). - Used non-referentially: I have control over him (having control or force is up).

\section{METONYMY:}

- Used referentially: Wall Street is in crisis (the street stands for the institution). - Used non-referentially: He is a brain (he is very intelligent).

The "STANDS FOR" relationship is simply a result of the domain-internal nature of metonymic mappings; that is, the false impression that metonymies obligatorily require a "STANDS FOR" relationship derives from the fact that metonymies are constructed upon a single conceptual domain, so it becomes difficult to map the relationship between source and target because one of the domains is already part of the other. To solve this, Ruiz de Mendoza (1997) claims for the existence of two types of metaphor from the point of view of the nature of the mapping process. We have one-correspondence metaphors (there is just one correspondence between the source and target domains; e.g. PEOPLE ARE ANIMALS, in which animal behaviour is mapped onto human behaviour) and many-correspondence metaphors (there are several correspondences between the source and target domains; e.g. LOVE IS A JOURNEY, in which the lovers are the travellers, the couple's shared goal is the destination, etc.).

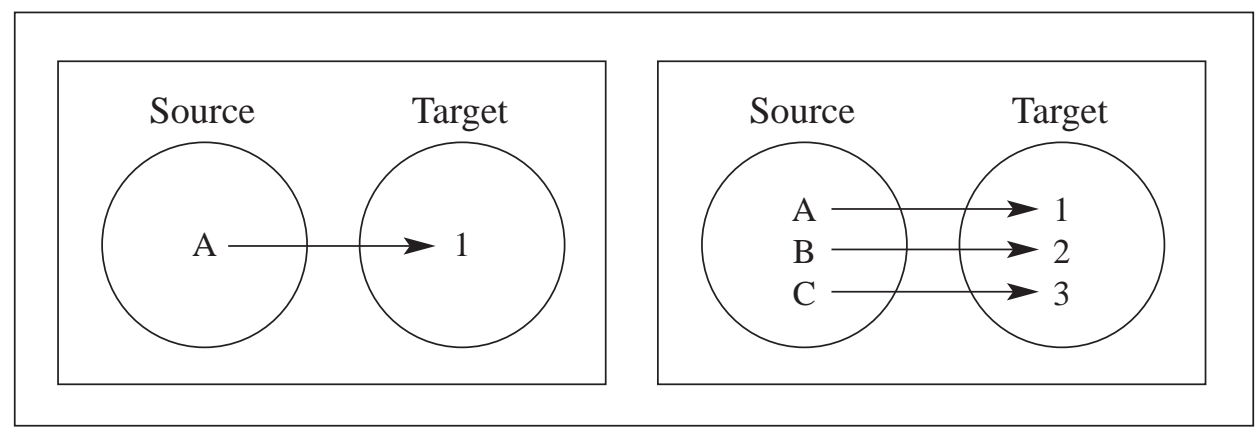

Figure 1. One-correspondence and many-correspondence metaphors. 
M etonymy is by nature a case of one-correspondence mapping, which may be divided into (a) target-in-source (the source domain stands for a target subdomain) and (b) source-in-target (a source sub-domain stands for a target domain) (cf. Ruiz de M endoza 2000; Ruiz de M endoza \& Pérez 2001)
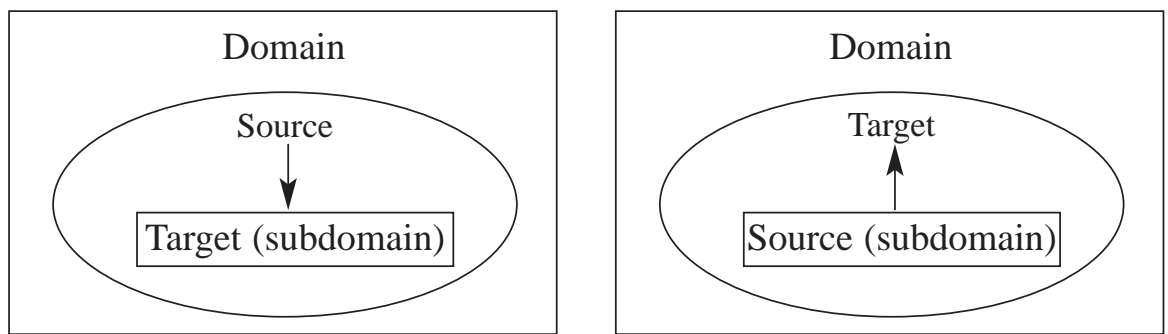

Figure 2. Target-in-source and source-in-target metonymies.

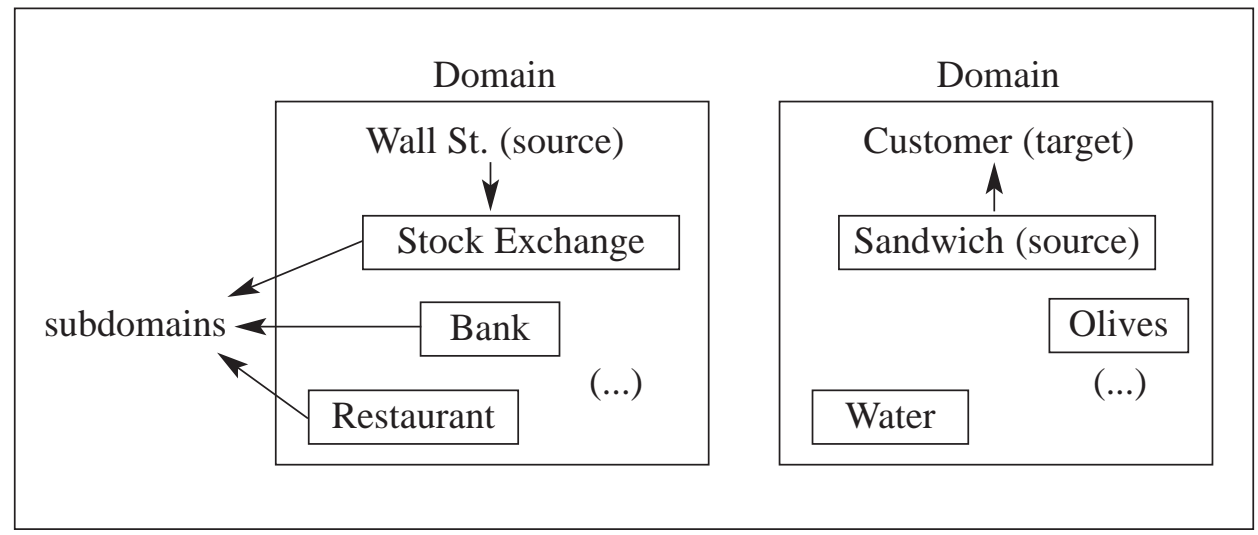

Figure 3. Examples of target-in-source and source-in-target metonymies.

These types of metonymic mapping correlate with the two basic functions of referential metonymy: first, source-in-target metonymies involve domain expansion (i.e. they provide full access to the reference domain, called by Ruiz de M endoza (2000) matrix domain, by means of one of its subdomains); second, target-in-source metonymies involve domain reduction, which leads to the highlighting of a relevant part of a domain. 


\section{M etaphor, metonymy, and metaphor-metonymy interaction}

A lthough I will focus my attention on the conceptual interaction section (see 3.3), I will make a few preliminary remarks on some metaphors and metonymies which, although they do not enter into patterns of interaction, deserve commentary.

\subsection{Metaphor}

We have some one-correspondence, structural metaphors (in terms of $L$ akoff and Johnson, 1980), and also primary (in words of Grady, 1997; 1998) metaphors related to eyes in which one concept is structured and understood in terms of another concept. Thus, we find eyes standing for look, gaze as in the following examples: his eyes turned toward her, he was under the watchful eyes of the teacher, to run one's eye over something, all eyes were on her... We may also find eye standing for attention as in: the carpet caught my eye, the eyes of the world will be on her, the company has been in the public eye a lot recently, to keep out of the public eye, to have one's eye on somebody/something, with an eye to something, etc. O ther instances can be found in eye standing for ability to do something correctly: to have an eye for detail/girls, to have a good eye (in shooting or in tennis). Also eye can be used with the meaning of perspective: a story seen through a child's eyes, through Christian eyes, etc.

We also find a special type of image metaphor, in which a mental image and its structure are mapped onto another mental image with its structure. $M$ etaphors of this kind can also be considered resemblance metaphors in terms of Grady (1997, 1998), since their source and target domains share some features which prompt the metaphoric mapping, as if we talk about the eye of a needle, the eye of a hurricane or storm, or the eye in a potato. To end with, there are examples as well of eyes meaning intelligence (an old metaphor coming from the Greek classical tradition, in which intelligence was symbolised by an owl with big eyes), and eyes as mirrors of one's soul (as has been said, eyes show our inner emotional states).

The expression to get a bird's eye view can be analysed as a metaphor as well: a bird flying and seeing things from the air (with a broad scope) maps onto a person acting in a certain way and getting a concrete perspective of things (generally ampler than other people's).

Finally, the expressions to be the owner of somebody's eyes and to be the apple of somebody's eyes can be interpreted as metaphors: in the former, we find 
that "owner of eyes" stands for "an indirectly controller of vision" (since there is something that prevents someone from doing anything but look at a certain person -for example, a girl-); in the latter, the eyes are presented as "having an apple," meaning "seeing an apple," which is directly linked to the metaphor "ownership or possession of an object is taking delight in it."

\subsection{M etonymy}

I will only devote a few lines within this section to describe an interesting low-level metonymy which is almost always brought about when we talk about eyes, without our realising as metonymy and metaphor have proved to be inferencing and reasoning mechanisms, and not just elements restricted to the poetic or literary fields. The following metonymy can appear in full interaction with metaphor as is shown in the next section. Hence, every time we refer to the colour of anybody's eyes (e.g. "his blue/grey/green/black/brown eyes") we are generating a metonymy which can be diagrammed as in figure 4 below.

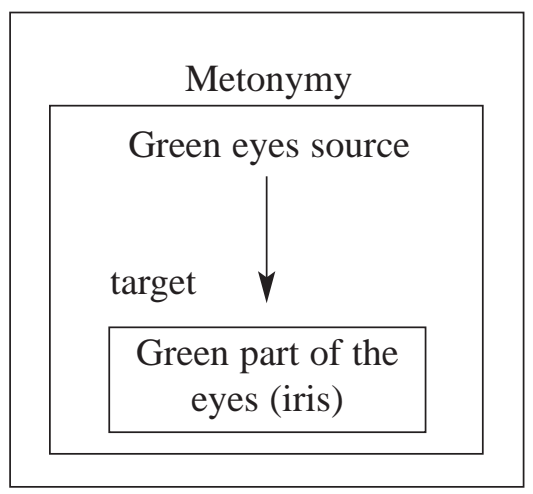

Figure 4. His green eyes.

On a experiential basis, this is obviously due to the fact that the colour of the iris is the most prominent part of the eye (in contrast to the white cornea and to the black pupil), thereby being extended to cover the whole of the eye. M oreover, the iris distinguishes and characterises different people. Hence, this metonymy involves domain reduction and highlighting operations by means of which the green and most relevant part of the eye -i.e. the iris- is brought into focus, thus giving it a more central status. 


\subsection{Interaction metaphor-metonymy}

3.3.1. Integrated interaction metaphor-metonymy. Starting by a poetic and romantic way of putting things, although we should always bear in mind that metaphor and metonymy are not mere rhetorical or literary devices but everyday cognitive and reasoning tools, we can analyse the expression that has given title to this article: imagine that you are before your sweetheart and you say as in a sort of poetic sentence "The emeralds of your face," "the pearls of your mouth..." Interestingly enough, the first expression refers to the sw eetheart's green eyes and can be diagrammed as follows.

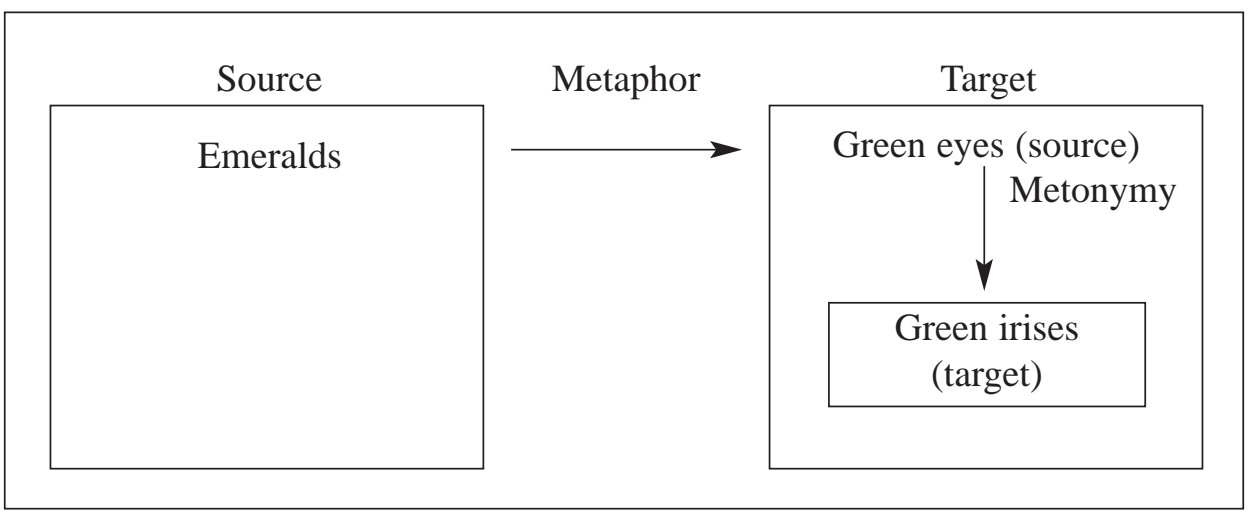

Figure 5. The emeralds of your face.

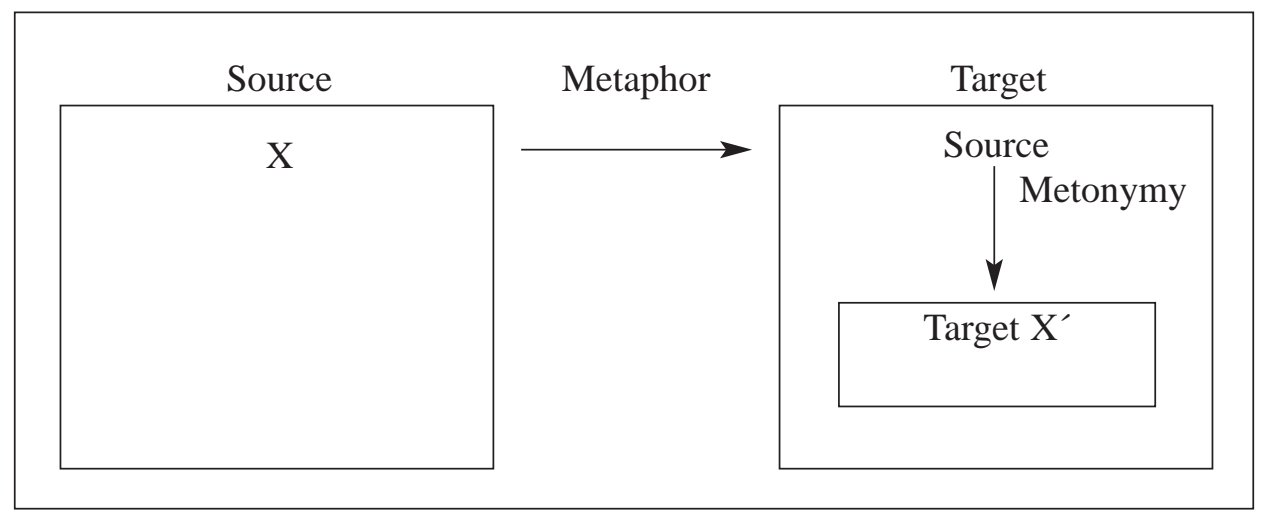

Figure 6. M etonymic reduction of a metaphoric target. 
This mapping can be also applied to similar constructions related to eyes such as the sapphires of her face, the waterfall of your face... This sort of patterns contain, as shown above, target in source metonymies within the metaphoric target, the metonymies thus having the function of highlighting that part of their source domain (the coloured iris) which is essential for the understanding of the metaphoric correspondence on which they work (emeralds $>$ green eyes). This pattern is very similar to the one which has been labelled by Ruiz de M endoza $\&$ Díez (2002) "metonymic reduction of one of the correspondences of the target domain of a metaphor," and can be represented as follows:

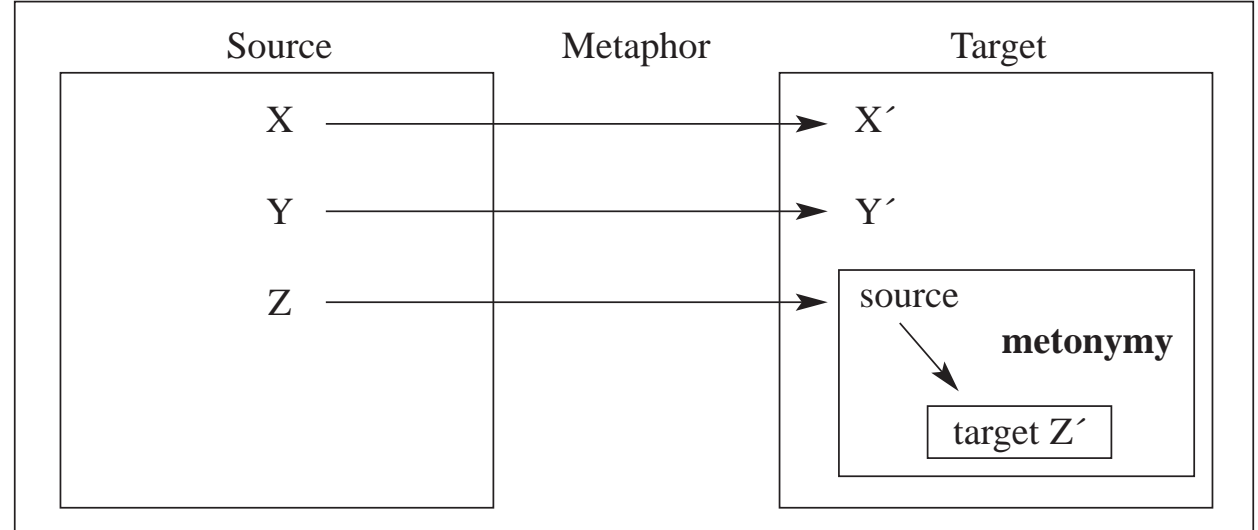

Figure 7. M etonymic reduction of one of the correspondences of the target domain of a metaphor.

This mapping is found in He opened my eyes, as represented below:

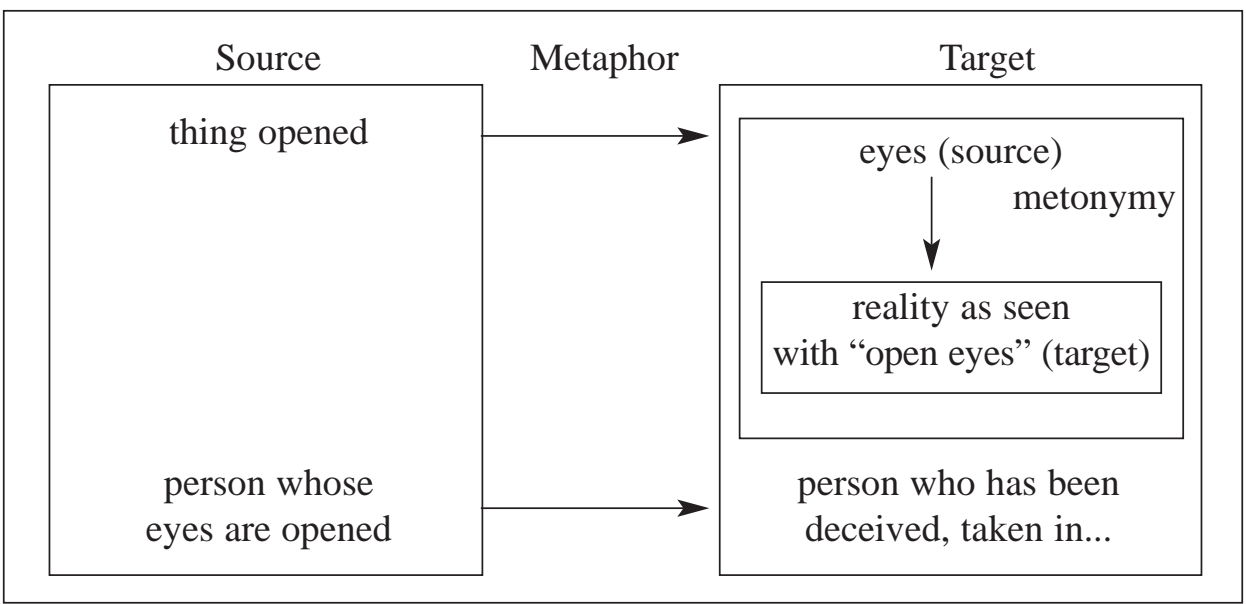

Figure 8. He opened my eyes. 
A different instance following the mapping described in figure 9 can be found in to keep an eye on someone, where eye metonymically stands for "vigilance". This is based upon the fact that the prototypical way to watch someone is to look at him, obviously since the body organ most directly involved in any visual activity is the eye. With respect to the metaphor, "keep" is figuratively used and thus involves a controlled action that affects another entity (e.g. "to keep something in a place" means that you have control over that entity). Similarly, when keeping an eye on someone, you control him/her through continuous watching, and this feature is mapped onto the target domain. Finally, notice how in one of the correspondences the target domain is expanded by the source-in-target metonymy EY E FOR VIGILANCE, highlighting the instrument of the action and giving it more prominence than the other correspondences so that it becomes the central one of the metaphor.

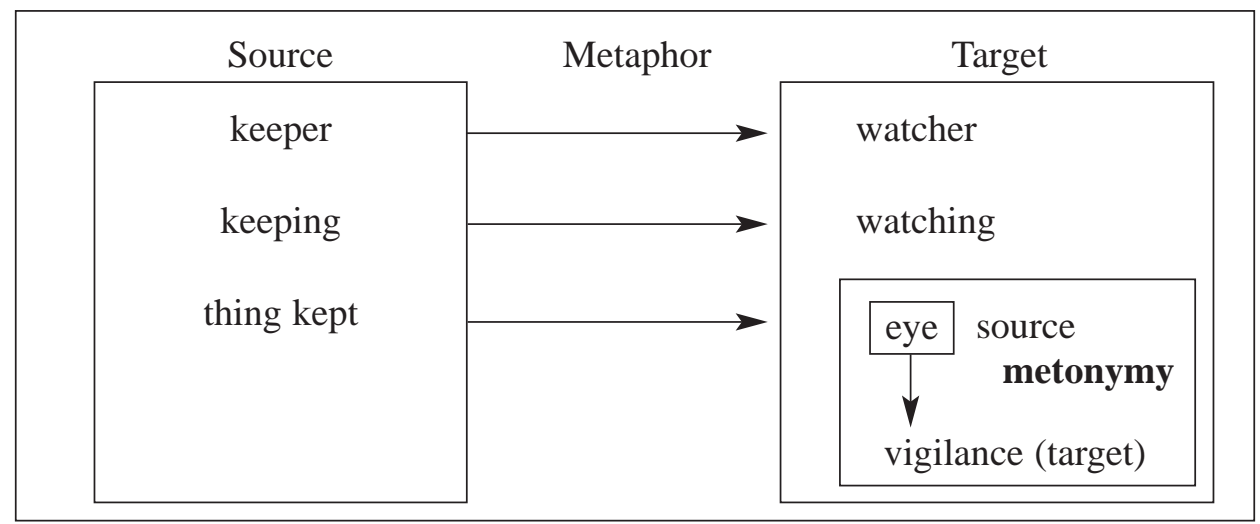

Figure 9. To keep an eye on someone.

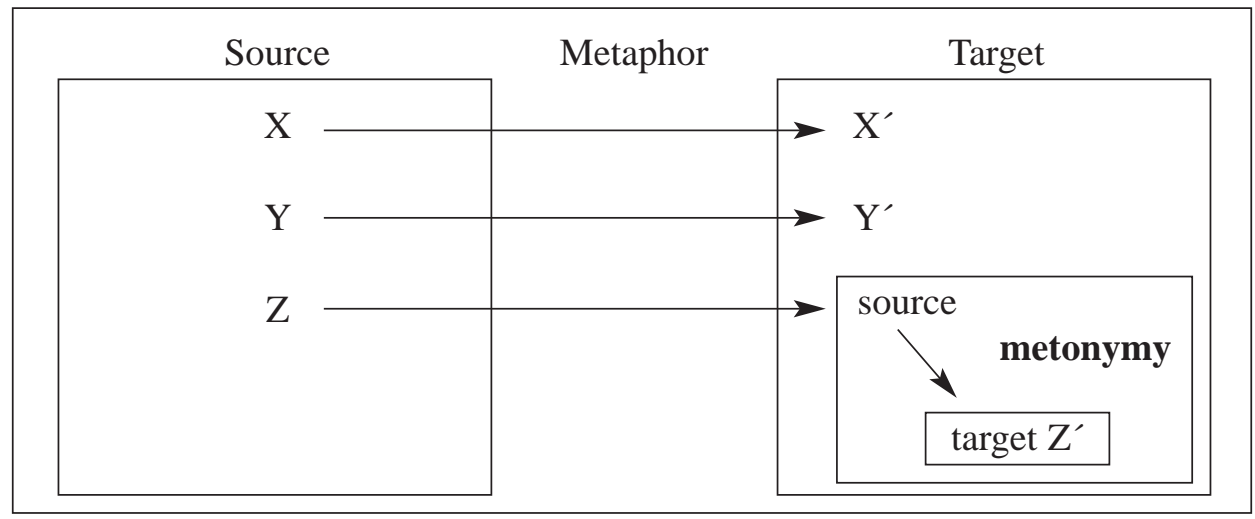

Figure 10. M etonymic expansion of one of the correspondences of the target domain of a metaphor. 
In the taxonomy established by Ruiz de M endoza \& Díez (2002), this pattern is labelled "metonymic expansion of one of the correspondences of the target domain of a metaphor," which is characterised by firstly, the fact that the correspondence where the metonymic mapping takes place is given more prominence than the other ones thus becoming the most central in the metaphor and, secondly, the fact that the metonymic expansion originates a focus on a specific subdomain of the reference domain ${ }^{2}$. Hence, these patterns show a double process of highlighting (one referred to the role of the correspondence in the metaphoric mapping and another related to highlighting a relevant feature of the matrix domain of the metonymy).

The following example tries to account for the fact that the metonymy included, which is of the source-in-target type, has the main function of developing the source of the metaphor in order to interpret it correctly. Suffice it to say that the role of this sort of metonymy is the same independently on whether it works on the source or on the target of the metaphoric mapping. In this example, a person performs the action of "peeling" his eyes in order to keep them wide open. Then, the target of this metaphor maps onto a more general situation in which a person keeps his eyes open as the way to be al ert against possible dangers or problems. Finally, there is a source-in-target metonymy with the main function of developing the target of the metaphoric mapping to get a full understanding of it.

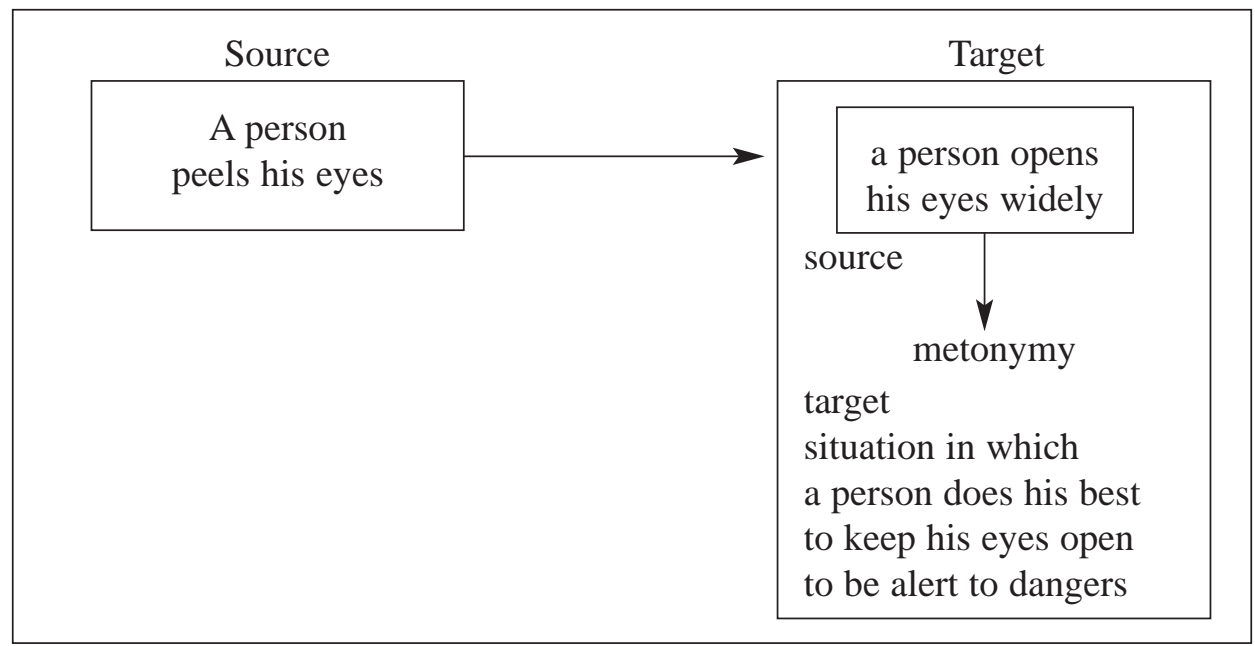

Figure 11. He peeled his eyes.

2. A ccording to Ruiz de M endoza, the matrix domain (see Ruiz de Mendoza \& Pérez, 2001; Ruiz de M endoza \& Díez, 2002). 


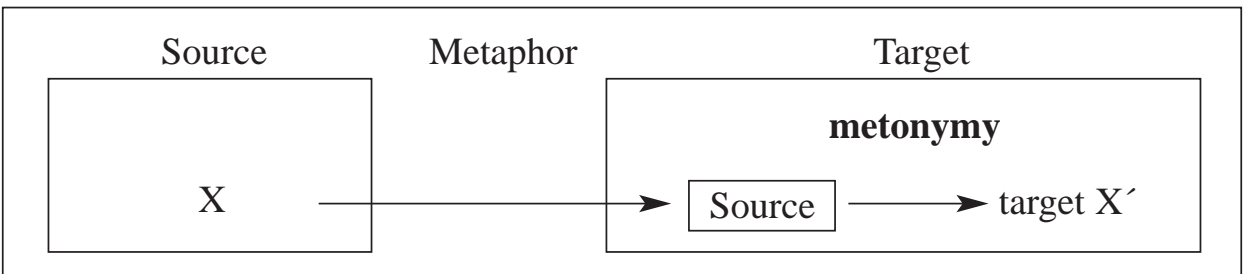

Figure 12. M etonymic expansion of a metaphoric target.

A nother example ${ }^{3}$ which points to the high productivity of this pattern is found in the expression to turn a blind eye to something, which can be explained as follows by means of diagrams.

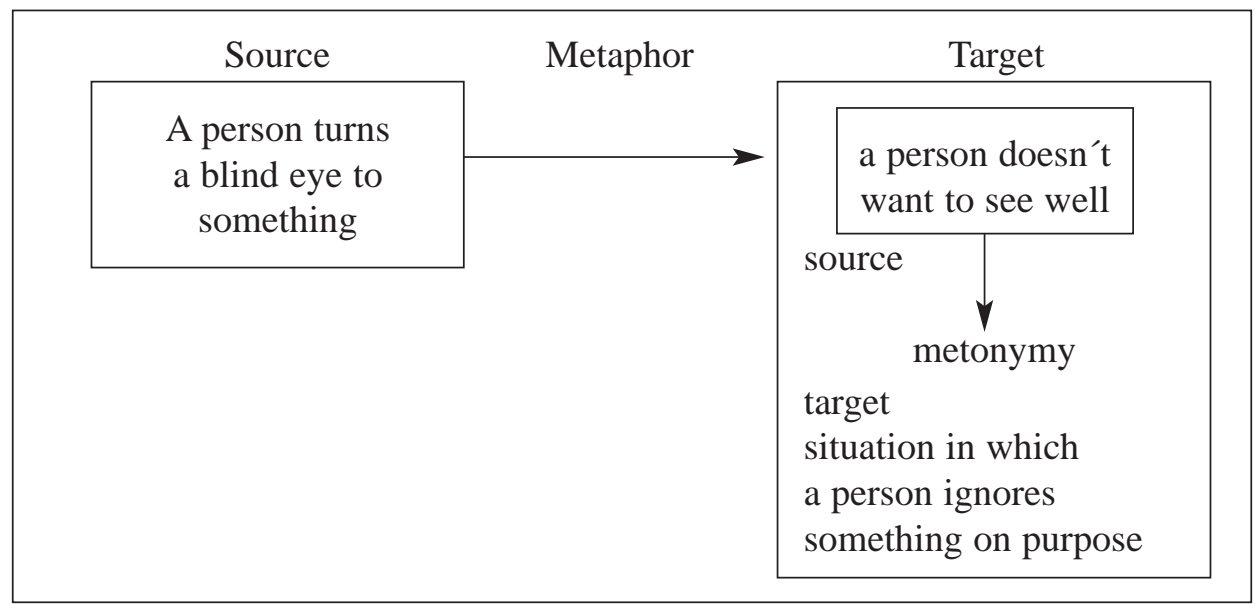

Figure 13. To turn a blind eye to something.

In the next expression, to close one's eyes to the facts, the source of the metonymy is a subdomain of the target, which provides us with the main elements in order to build the metaphoric mapping (the output of the metonymic mapping is the input to the metaphor) while focusing on only one of the correspondences (i.e. a person ignores a problem or situation). This is not possible with

3. N ote that more instances that are not analysed since they follow similar patterns are: to feast one's eyes on something, to go with the eyes closed, to take an eye for an eye (biblical), he cannot believe his eyes, to hit someone in the eyes, etc. 
metonymies where the source is not a subdomain of the target, as Ruiz de Mendoza \& Díez here noticed (2002). This example can be labelled a "metonymic expansion of a metaphoric source", always following this pattern:

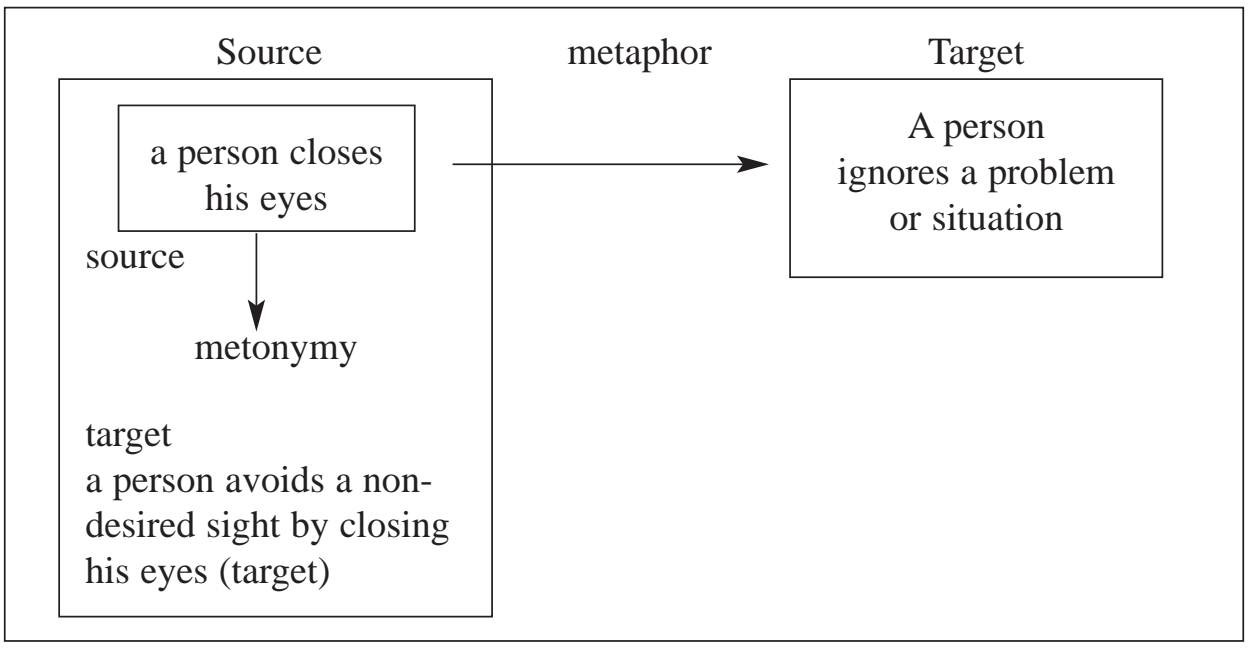

Figure 14. To close one's eyes to the facts

We may find the similar pattern in to cry one's eyes out.

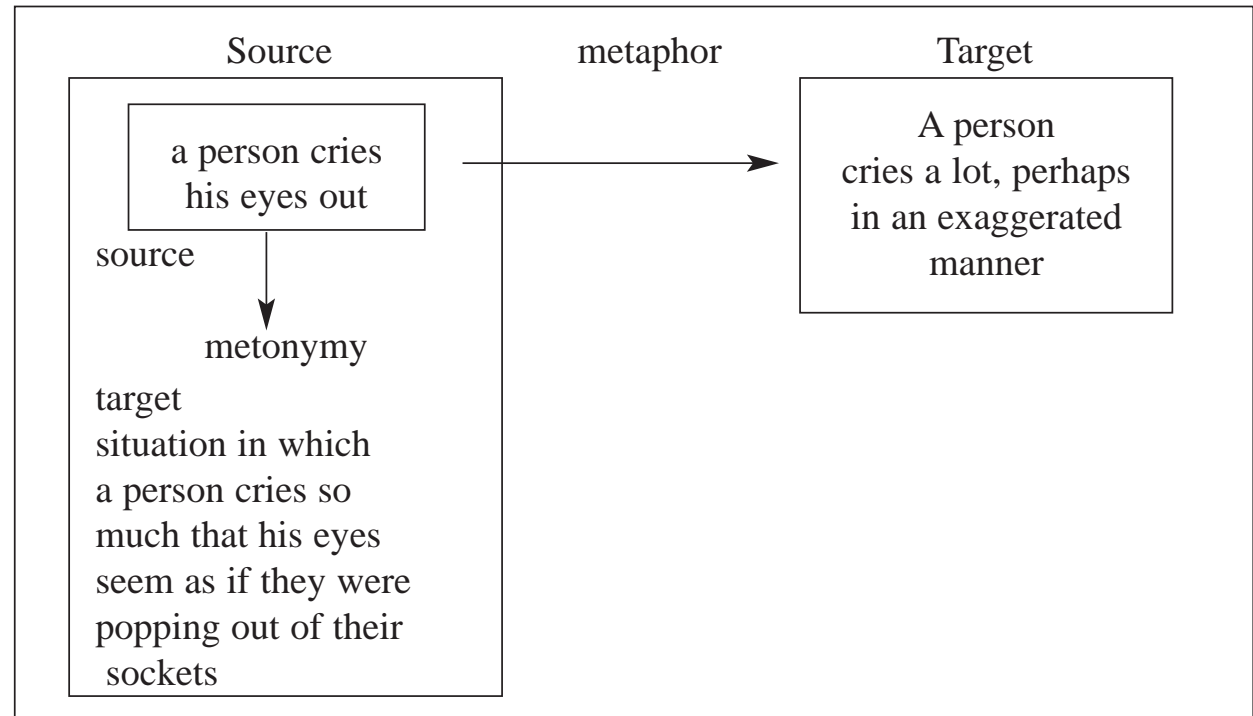

Figure 15. To cry one's eyes out. 


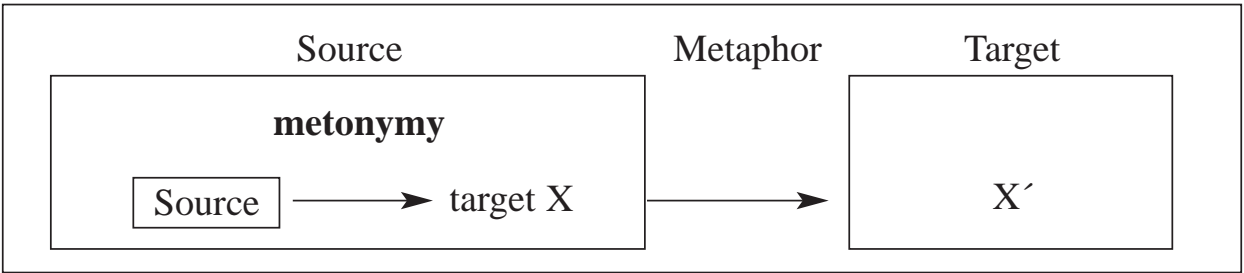

Figure 16. M etonymic expansion of a metaphoric source.

A different pattern can be found in instances such as to have hawk's eyes ${ }^{4}$, in which the metonymy is of the target-in-source type (i.e. "hawk's eyes" standing for "excellent eyesight", since hawks are characterised for having extraordinary eyesight, which maps onto the subdomain of a person's eyesight). This leads to patterns labelled "M etonymic reduction of one of the correspondences of the metaphoric source".

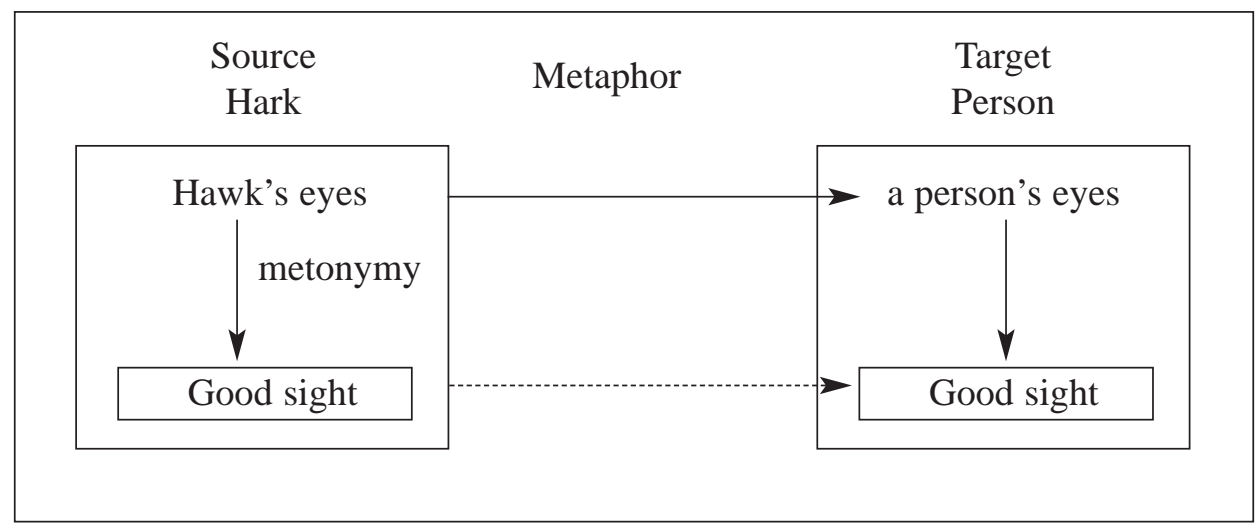

Figure 17. To have hawk's eyes.

4. N otice that this expression may be contrasted to to have calf's eyes or doe eyes, leading to "pitying look" instead of "a good sight"; or to to have a roving eye, leading to "lascivious look". 


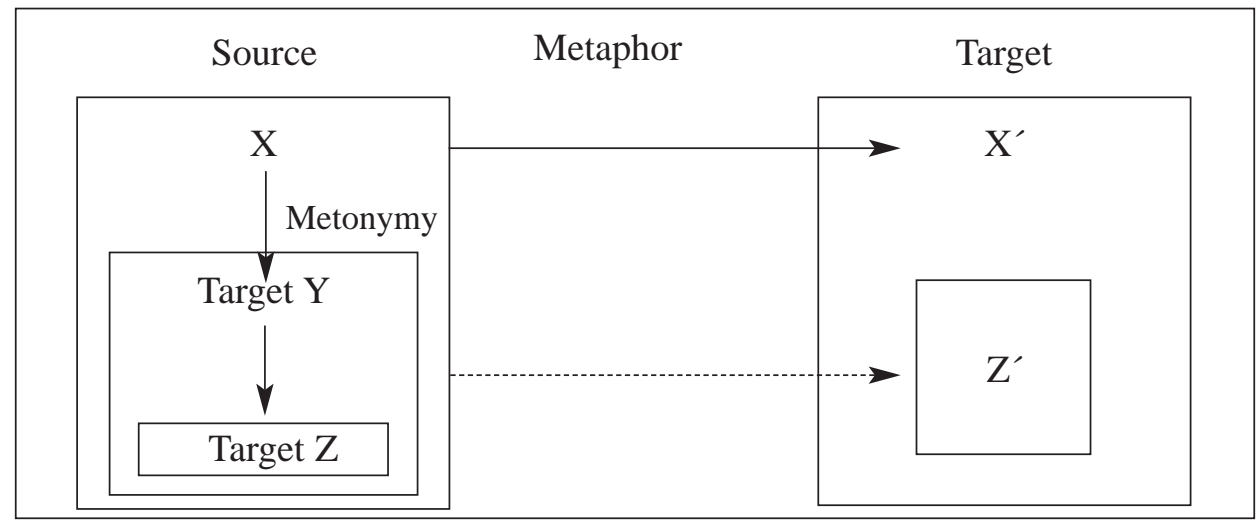

Figure 18. M etonymic reduction of one of the correspondences of the metaphoric source.

In order to finish this section, the last interactional pattern can be exemplified by the expression To eyeball someone, in which one of the correspondences within the metaphoric source is developed metonymically ("eyeball" for the action of looking using all the cavity of the eye). The metonymy has the function of highlighting the possibility of "eyeball" to become the action of "looking at someone up and down" (conscientiously). So, the source of the metonymy becomes the one with the highest degree of prominence since the metonymy itself puts into focus one of the correspondences in the activation of the metaphoric source. This pattern is labelled "metonymic expansion of one of the correspondences of the source domain of a metaphor."

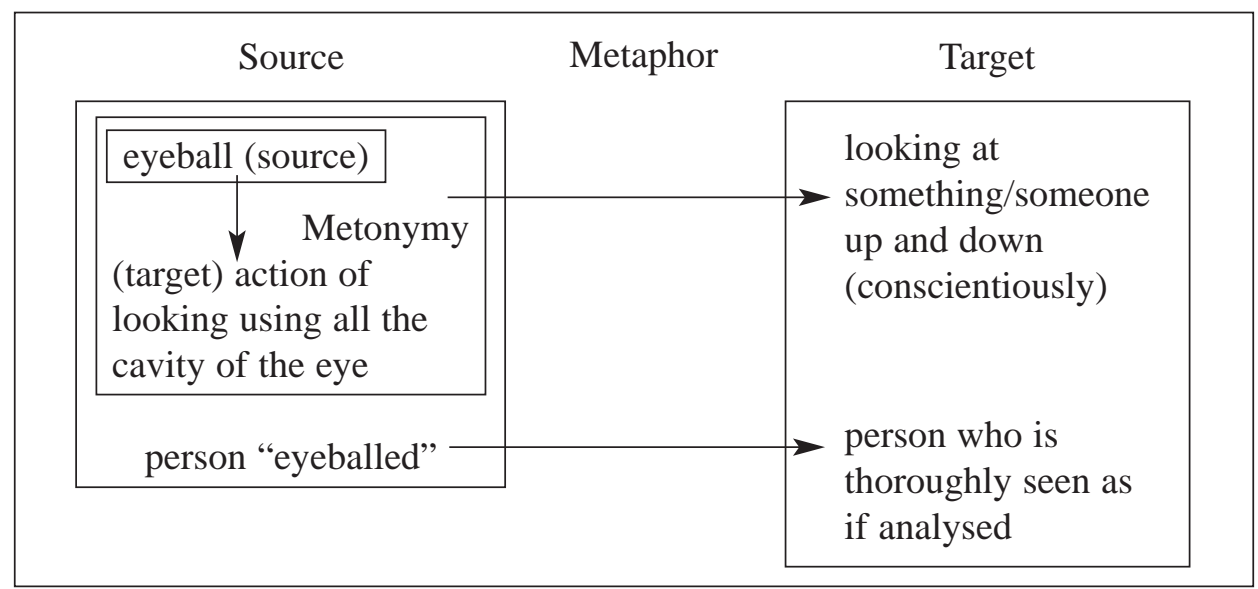

Figure 19. To eyeball someone 


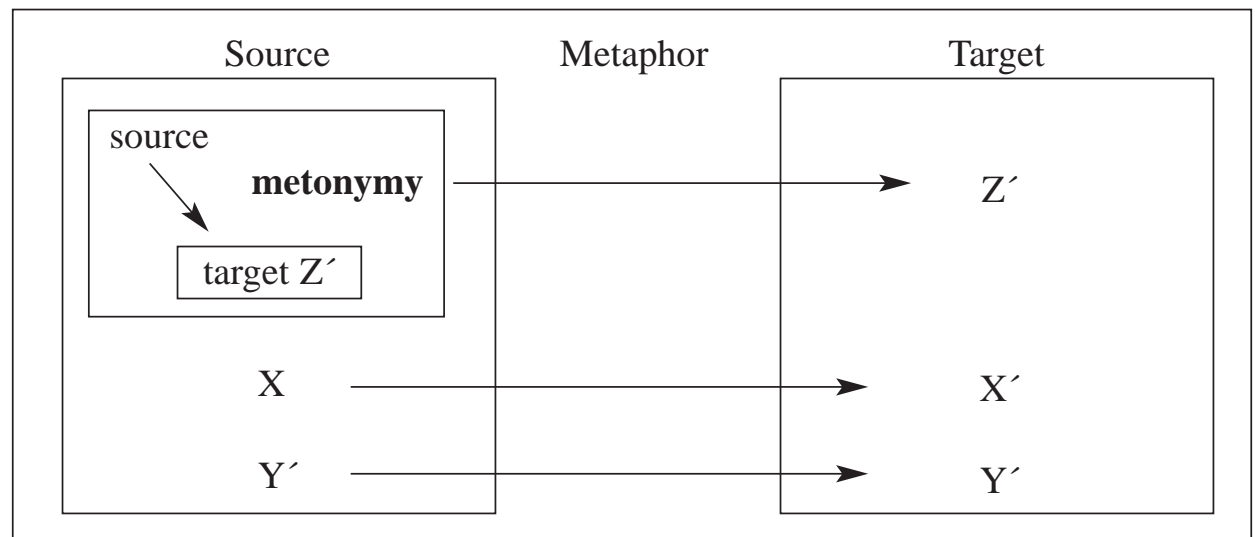

Figure 20. M etonymic expansion of one of the correspondences of the source domain of a metaphor.

\subsubsection{Sequenced interaction metaphor-metonymy}

In order to address this section, we will have in mind the following patterns as discussed in section 3.3.1 above:

(1) M etonymic expansion of a metaphoric source.

(2) M etonymic expansion of a metaphoric target.

(3) M etonymic reduction of one of the correspondences of the target domain of a metaphor.

(4) M etonymic expansion of one of the correspondences of the target domain of a metaphor

(5) Metonymic expansion of one of the correspondences of the source domain of a metaphor.

(6) M etonymic reduction of the metaphoric source.

(7) M etonymic reduction of a metaphoric target.

Since metonymy is subsidiary to metaphor in all these patterns, i.e. it modulates the kind of access we have to either the source or the target, it would be tempting to dismiss the problem by thinking that the metonymic mapping simply takes place after the metaphoric framework has been invoked. But this is not exactly right. For example, patterns (1) and (5) require not so much the activation of the metonymy in the metaphoric source as the activation of the metonymy in 
order to create the metaphoric source. So, in this pattern metonymic activation both precedes and is a prerequisite for metaphor. However, it is also true that metonymy is part of - and in this sense ancillary to- metaphor. In contrast to what is the case with (1) and (5), in patterns (2), (3), (4) and (7) the metonymic activity within the metaphoric target is the last stage of the interpretation process. In fact, metonymy is necessary in order for all relevant correspondences with the source to be fully worked out. Finally, pattern (6) shares with (1) and (5) the function of preparing the metaphoric source for the mapping operation to be possible, but in this case the metaphoric source is activated before any metonymic activity takes place. As we have pointed out before, the metonymy here has the function of highlighting the central correspondence of the metaphoric mapping while the structural relationship between the highlighted subdomain and its corresponding matrix domain is additionally brought to bear upon the meaning derivation process.

The issue of sequencing does not end here. We believe that in order to understand all its intricacies it is necessary to take into account both the ontological status of the domains involved in the interaction and the level of genericity of the mappings. This takes us to our second proposed question about the definitional relationship between metaphor and metonymy ${ }^{5}$. Consider first the sentence Peter foxed me, which can be roughly paraphrased as 'Peter was able to deceive me by acting in a cunning way'. This paraphrase reveals two stages of interpretation. One, where -through the metaphor PEOPLE ARE ANIMALS- attributed animal behaviour is mapped onto human behaviour: Peter is as clever and deceitful as foxes are thought to be. A nother, in which Peter is seen as acting according to the behavioural traits ascribed to him. This second stage is the result of the application of the high-level metonymy A GENT FOR ACTION ${ }^{6}$, which has the effect of converting an ontological metaphor into the equivalent of a situational metaphor ${ }^{8}$. Thus, the interaction process in P eter foxed me is carried out al ong the lines of pattern (2) above, although with one crucial difference. Here the

5. See Herrero (2002).

6. By high-level metonymy, we understand a metonymy in which both the source and target domains are generic cognitive models.

7. In which abstract entities are dealt with as if they were physical objects or substances, as in TIME IS SOMETHING MOVING.

8. Which works on the basis of deriving generalisations from a conventional situation, and which usually appear in combination with a metonymic mapping; this metonymic connection has the function of projecting a concrete picture onto a wider situation; e.g. To get up on one's hind legs. 
metonymic development of the target has consequences in terms of the ontological status of the resulting metaphor where we have more than one correspondence at issue: we think of Peter acting in such a way that his actions result in the speaker being tricked. This goes beyond saying that Peter is astute, as in Peter is a fox, where there is only one correspondence. A dditionally, it may be observed that the sequencing process we have described for this metaphor has much in common with a case of what Ruiz de Mendoza \& Díez (2002: 515) have called "double metonymy".

Metonymies are by definition one-correspondence mappings. However, when a metonymic model is further developed into a high-level action scenario, as exemplified in figure 10, the result is very similar to pattern (2) of metaphormetonymy interaction. We postulate that this is possible because this pattern is initially created on the basis of a one-correspondence metaphor. Indirectly, this shared property of both interaction patterns is evidence in favour of Ruiz de $M$ endoza's distinction between one-correspondence and many-correspondence metaphors and the existence of a metaphor-metonymy continuum where the former are closer to metonymy than the latter both in terms of their structure and their functionality. In this connection, Ruiz de M endoza has observed that onecorrespondence metaphors may be used referentially (e.g. There's the nasty rat who betrayed me), like metonymies. We additionally note that this kind of metaphor enters into the same interactional patterns as metonymy.

This pattern of interaction, where an ontological metaphor acquires properties typically ascribed to situational metaphors, is very productive, as shown by Herrero (2002). N evertheless, a different but related sequencing process is found in the case of other ontological metaphors which do not enter into situational patterns. Contrast the sentence 0 ur reps are our eyes in the market with 0 ur reps eyed up the market. In the former, we have only one interpretation stage where 'eye' maps onto 'observers, informers', in such a way that we think of the reps as faithful observers and analysers of what happens in the market. In the latter, the metaphoric source 'eye' maps onto the expanded notion of "study, observe, analyse thoroughly". This expansion is the result of high-level metonymic activity whereby an object -in this case an organ- involved in an action may stand for the action. This interaction pattern resembles pattern (1) above and results in a change from an ontological to a situational metaphor where the instrumental character of the EYE is highlighted. The two stages of this interactional process are diagrammed in figure (20) below. 
First stage: O ntological metaphor.

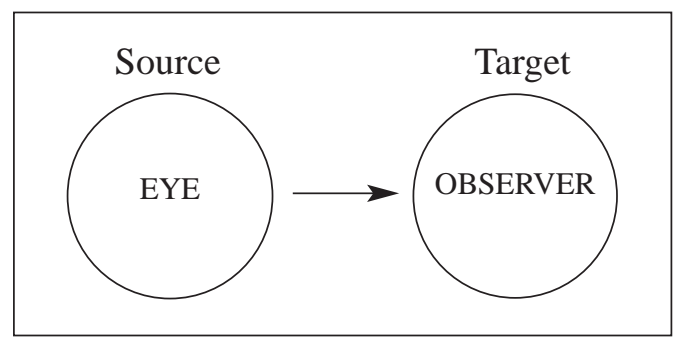

Second stage: High-level metonymy: OBJECT/ORGA N INV OLVED IN AN ACTION FOR THE ACTION.

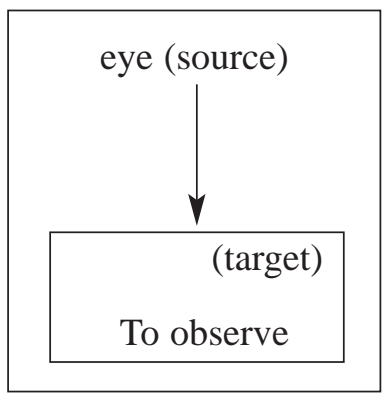

Figure 21. Sequential interaction metaphor > metonymy: 0 ur reps eyed up the market.

\section{Conclusion}

B esides demonstrating that the semantic domain related to eyes, being essential for our everyday experience, has a strong linguistic impact which may be appreciated in all the patterns and constructions it generates and that have briefly been analysed before, the present paper has not only confirmed that conceptual interaction is fully regulated and constrained by a limited set of interactional patterns, but it has also provided additional evidence in support of this thesis in the domain of metaphor-metonymy interaction. Furthermore, we have been able to examine the question of the sequential arrangement (or sequencing) of interaction operations in relationship with the issue that occupies us within this article. Thus, after having used this analysis in order to cast light upon the definitional relationship between metaphor and metonymy, we can also support the idea that the form sequential arrangement takes in an interactional pattern is related to the ontological status of the result of an integration process. Finally, we have been able to find 
one more interactional pattern, which has escaped Ruiz de Mendoza \& Díez's notice, namely the one labelled "M etonymic reduction of a metaphoric target."

\section{R eferences}

B arcel ona, A, 2000. "Types of arguments for metonymic motivation of conceptual metaphor". Metaphor and M etonymy at the Crossroads, Ed, A. B arcelona. Berlin/New York: M outon de Gruyter. 31-58.

B artsch, R, 2002. "Generating polysemy: metaphor and metonymy". M etaphor and $M$ etonymy in Comparison and Contrast. Eds. R. Dirven \& R. Pörings. Berlin, N ew York: M outon de Gruyter. 49-74.

Coulson, S.\& T, Oakley. 2001, "M etonymy and conceptual blending". Available from http://cogsci.ucsd. edu/-coulson/metonymy-new.htm

Croft, W. "The role of domains in the interpretation of metaphors and metonymies". Metaphor and M etonymy in Comparison and Contrast. Eds. R. Dirven \& R. Pörings. Berlin. N ew Y ork: M outon de Gruyter. 161-206.

Cuenca, MJ.\& J. Hilferty. 1999. Introducción a la lingüística cognitiva. $B$ arcelona: A riel.

Dirven, R. "M etonymy and metaphor: different mental strategies of conceptualisation". Metaphor and Metonymy in Comparison and Contrast. Eds. R. Dirven \& R. Pörings, B erlin, N ew Y ork: M outon de Gruyter, 75-112,

Fauconnier, G, \& M. Turner. 1996, "Blending as a central process of grammar". Conceptual Structure, Discourse and Language. Ed. A, Goldberg, Stanford, CA: CSLI Publications- 113-130.

- 1998, "Conceptual integration networks". Cognitive Science 22 (2): 133-187.

- 2001. "Conceptual integration networks" (expanded version). A vailable from http://www.mform.umd.edu/EdRes/Colleges/ARHU/D epts/ English/engfac/ M turner/cin. web.

Fillmore.C. 1985. "Frames and the semantics of understanding". Quaderni di Semantica 6, 2: 222-254.

Fornés, M - \& F.J . Ruiz de M endoza. 1996. "Esquemas de imágenes y construcción del espacio". RILCE 14, 1: 23-43.

Gibbs, R, 1994, The Poetics of Mind. Figurative Thought, Language and Understanding. Cambridge U niversity Press: Cambridge. 
Goossens, L. "M etaphtonymy: the interaction of metaphor and metonymy in expressions for linguistics action". M etaphor and M etonymy in Comparison and Contrast. Eds. R. Dirven \& R. Pörings. Berlin, New York: M outon de Gruyter. 349-378.

Grady, J. 1997. "THEORIES ARE BUIL DINGS revisited". Cognitive Linguistics 8.-261290.

- 1998. "The Conduit M etaphor revisited: a reassessment of metaphors for communication". Conceptual Structure, Discourse, and Language. Ed. J.P. K oenig. B uffal o: CSLI Publications. 205-218.

Grady, J., T. Oakley \& S. Coulson. 1999. "B lending and metaphor". M etaphor in Cognitive Linguistics. Eds. R. Gibbs \& G- Steen- Philadelphia: John Benjamins, 101-124.

Grady, J.\& C. Johnson. "Converging evidence for the notions of subscene and primary scene". M etaphor and M etonymy in Comparison and Contrast. Eds. R. Dirven \& R. Pörings. B erlin, N ew York: M outon de Gruyter, 533-554.

Herrero, J. 2002. "Sequencing and integration in metaphor-metonymy interaction". RESLA, 15: 73-91.

Kövecses, Z. \& G. Radden. 1998. "M etonymy: developing a cognitive linguistic view". Cognitive Linguistics 9, 1: 37-77.

Johnson, M. 1987, The Body in the Mind: the Bodily Basis of Meaning, Imagination and Reason. Chicago: University of Chicago Press.

Lakoff, G. 1987. Women, Fire, and Dangerous Things: What Categories Reveal About the Mind. Chicago: University of Chicago Press.

- 1989. "Some empirical results about the nature of concepts". Mind \& Language 4, 1-2: 103-129.

- 1993. "The contemporary theory of metaphor". M etaphor and Thought, $2^{\text {nd }}$. ed. Ed. A . Ortony. Cambridge University Press. 202-251.

Lakoff, G. \& M . Johnson, 1980. M etaphors We Live By. Chicago \& London: The University of Chicago Press.

- 1999. Philosophy in the Flesh. The Embodied Mind and Its Challenge to Western Thought. New York: B asic Books.

Lakoff, G, \& M. Turner 1989. More Than Cool Reason. A F ield Guide to Poetic M etaphor. Chicago: The University of Chicago Press.

Langacker, R.W. 1987. F oundations of cognitive Grammar, vol. 1. Theoretical Prerequisites. Stanford, Cal.: Stanford U niversity Press. 
L angacker, R.W. 1993. "Reference-point constructions". Cognitive Linguistics 41; 1-38.

- 1997. "The contextual basis of Cognitive Semantics". Language and Conceptualization. Eds. J, Nuyts \& E. Pederson. Cambridge: Cambridge University Press. 229-252.

N unberg. G. 1995. "Transfers of meaning". J ournal of Semantics 12: 109-132.

Otal, J.L., \& F.J. Ruiz de Mendoza. 2002. Metonymy, Grammar, and Communication. Granada: Comares.

Panther, K.-U.\& L. Thornburg. 1999. "The potential for actuality metonymy in English and Hungarian". Metonymy in Language and Thought. Eds. K.U. Panther \& G. Radden. A msterdam/Philadelphia: John Benjamins. 333-359.

Peña Cervel, S. 1998. "The role of the control ICM and of image-schemata in metaphors for understanding emotions". The Pragmatics of U nderstanding and M isunderstanding. Ed. B. Penas. Universidad de Zaragoza. 175-184.

Peña Cervel, S. 1999. "Subsidiarity relationships between image-schemas: an approach to the force schema". J ournal of English Studies 1: 187-207.

- 2001. "Situational metaphors and metonymy". Talk presented at the I1th Susanne Hübner Seminar. University of Zaragoza.

Pérez Hernandez, L.\& F.J. Ruiz de M endoza Ibañez, 2002. "Grounding, semantic motivation, and conceptual interaction in Indirect Directive Speech A cts". J ournal of Pragmatics 34/3: 259-284.

Perez Hernandez, L. (in press). "Blending vs. conceptual interaction in the construction of illocutionary meaning: counterfactual pieces of advice". Revista Alicantina de Estudios Ingleses.

Radden, G. "How metonymic are metaphors?". Metaphor and Metonymy in Comparison and Contrast. Eds. R. Dirven \& R. Pörings. Berlin, New York: M outon de Gruyter, 407-434.

Riemer, N. "When is a metonymy no longer a metonymy?". Metaphor and M etonymy in Comparison and Contrast. Eds. R. Dirven \& R. Pörings. B erlin, New Y ork: M outon de Gruyter. 379-406.

Ruiz de Mendoza Ibañez, F.J. 1997, "M etaphor, metonymy and conceptual Interaction". Atlantis 19, 1:281-295.

- 1998a- "Blended spaces and the pragmatic approach to cognition". The Intertextual Dimension of Discourse. Ed. B. Penas. Universidad de Zaragoza: Servicio de Publicaciones. 233-244 
Ruiz de M endoza Ibañez, F.J . 1998b. "On the nature of blending as a cognitive phenomenon". J ournal of Pragmatics 30, 3; 259-274.

- 1999a. Introducción a la teoría cognitiva de la metonimia. Granada: M étodo Ediciones.

- 1999b. "From semantic underdetermination via metaphor and metonymy to conceptual interaction". LAU D 492. Essen.

- 2000. "The role of mappings and domains in understanding metonymy". Metaphor and M etonymy at the Crossroads. A Cognitive Perspective. Ed. A. B arcelona. B erlin, N ew Y ork: M outon de Gruyter. 109-132.

Ruiz de Mendoza Ibañez, F.J. \& Olga I. Díez Velasco. 2001. "High-level metonymy and linguistic structure". U npublished draft.

- 2002. "M etonymic types and anaphoric reference". Unpublished draft.

- 2002. "Patterns of conceptual interaction". Metaphor and Metonymy in Comparison and Contrast. Eds. R. Dirven \& R. Pörings. Berlin, New York: M outon de Gruyter; 489-532.

Ruiz de M endoza Ibañez, F.J . \& L. Pérez Hernández. 2001. "M etonymy and the grammar: motivation, constraints and interaction". Language \& Communication 21-4: 321- 357.

Sperber, D. \& D. Wilson. 1993. "Linguistic form and relevance". Lingua 90: 125.

- 1995. Relevance. Communication and Cognition. Oxford: Basil Blackwell. (2nd. ed.).

Stirling, L. 1996. "M etonymy and anaphora". Belgian J ournal of Linguistics 10 (Coherence \&. Anaphora). 69-88.

Taylor, J.R. 1995. Linguistic Categorization. Prototypes in Linguistic Theory. Oxford: Clarendon. 2nd. ed.

Turner, M \& \& G. Fauconnier, 1995. "Conceptual integration and formal expression". M etaphor and Symbolic Activity 10: 183-204.

- 2002, "M etaphor, metonymy, and binding". Metaphor and Metonymy in Comparison and Contrast. Eds. R. Dirven \& R. Pörings. Berlin. New York: M outon de Gruyter. 469-488.

Warren. B. "A $n$ alternative account of the interpretation of referential metonymy and metaphor". Metaphor and M etonymy in Comparison and Contrast. 